\title{
Değişik Zamanlarda Hasat Edilen Farklı Tipteki Şeker Pancarı (Beta vulgaris var. saccharifera L.) Çeşitlerinin Verim ve Bazı Kalite Özelliklerinin Belirlenmesi
}

\author{
Bekir TOSUN ${ }^{*}$, Tahsin KARADOĞAN ${ }^{2}$, Arif ŞANLI ${ }^{3}$ \\ 1,2,3Isparta Uygulamalı Bilimler Üniversitesi, Ziraat Fakültesi, Tarla Bitkileri Bölümü, 32260, Isparta, Türkiye \\ ${ }_{1}^{1}$ (ORCID:https://orcid.org/0000-0002-2470-3865) \\ ${ }^{2}$ (ORCID:https://orcid.org/0000-0002-3422-8295) \\ ${ }^{3}$ (ORCID:https://orcid.org/0000-0002-5443-2082)
}

(Alınış / Received: 04.06.2018, Kabul / Accepted: 30.11.2018, Online Yayınlanma / Published Online: 26.02.2019)

\section{Anahtar Kelimeler}

Şeker pancarl,

Beta vulgaris var. saccharifera L., Ceșit,

Hasat Zamani,

Verim,

Kalite

\begin{abstract}
Özet: Isparta ekolojik koşullarında 2012 ve 2013 yıllarında yürütülen bu araştırmada farklı zamanlarda hasat edilen (çıkıştan 140, 155, 170, 185 ve 200 gün sonra) değișik tiplerdeki șeker pancarı çeșitlerinin (Begonia, Aranka ve Esperanza (N tipi), Sandrina ve Esperia (NZ tipi), Felicita ve Agnessa (Z tipi) verim ve bazı kalite özellikleri incelenmiştir. En yüksek kök gövde ve biyolojik verim erken sökümde Aranka, geç sökümde ise Esperia çeșitlerinden elde edilmiștir. En düșük $\alpha$-amino azot miktarı erken sökümde Aranka (5.68 mmol/100g), geç sökümde ise Esperia (2.05 mmol/100g) ve Esperanza $(2.11 \mathrm{mmol} / 100 \mathrm{~g})$ çeşitlerinde belirlenmiştir. Erken ve geç sökümlerde Z tipi olan Felicita ve Agnessa çeşitleri en yüksek polar şeker oranına sahip olmuştur. En yüksek polar şeker verimi erken sökümde Aranka $(1490 \mathrm{~kg} / \mathrm{da})$, geç sökümde ise Esperia $(1867 \mathrm{~kg} / \mathrm{da})$ ve Sandrina $(1860 \mathrm{~kg} / \mathrm{da})$ çeşitlerinden elde edilmiștir. Çalışmada, Isparta koşullarında yüksek verim ve teknolojik olgunluk bakımından Aranka ve Begonia çeşitlerinin 200 gün, diğer çeșitlerin ise en az 185 günlük vejetasyon dönemini tamamlaması gerektiği sonucuna varılmıştır.
\end{abstract}

\section{Determination of Yield and Some Quality Traits of Varied Types of Sugarbeet (Beta vulgaris var. saccharifera L) Cultivars Harvested at Different Times}

\section{Keywords}

Sugar beet,

Beta vulgaris var. saccharifera L.,

Cultivars,

Harvest time,

Yield,

Quality

\begin{abstract}
The present study was carried out at Isparta ecological conditions during 2012 and 2013 crop seasons to determine the effects of different harvest times $(140,155,170,185$ and 200 days after emergence) at different types of sugarbeet cultivars (Begonia, Aranka and Esperanza ( $N$ types), Sandrina and Esperia (NZ types), Felicita and Agnessa ( $\mathrm{Z}$ types) on yield and some quality parameters.The highest sugarbeet yield and biyological yield per decare were obtained from Aranka cultivar at early harvest times and from Esperia cultivar at lates harvest times. The lowest amount of $\alpha$-amino nitrogen were determined from Aranka (5.68 mmol/100g) at early harvest and from Esperia $(2.05$ $\mathrm{mmol} / 100 \mathrm{~g})$ and Esperanza $(2.11 \mathrm{mmol} / 100 \mathrm{~g})$ cultivars at late harvest time. The highest polar sugar content were determined from Felicita and Agnessa cultivars ( $\mathrm{Z}$ types) at early and late harvests. The highest polar sugar yield per decare were obtained from Aranka cultivar (1490 kg/da) at early harvest and from Esperia cultivar $(1867 \mathrm{~kg} / \mathrm{da})$ and Sandrina $(1860 \mathrm{~kg} / \mathrm{da})$ cultivars at late harvest. It was concluded that Aranka and Begonia cultivars should be completed 200 days while other cultivars at least 150 days of vegetation period in terms of high root yield and technological quality in Isparta conditions.
\end{abstract}




\section{Giriş}

Şeker pancarının başlangıçtaki şeker içeriği \%1,3 oranında iken ıslah edilerek günümüzde \% 24'lere kadar çıkarılmıştır [1]. Islah çalışmaları ile şeker oranı, verim ve hastalıklara dayanıklılı gibi özellikleri bakımından E (kitle verim tip), N (kitle ve şeker verimi kombine tip), Z (şeker oranı yüksek tip), NZ (verim ve şeker tipi), ZZ (ekstra yüksek şeker tipi sslah materyali), CR (cercospora'ya dayanıklı) ve GR (yeşilbaş tipi) gibi farklı şeker pancarı tipleri geliștirilmiștir. Şeker pancarı hastalıklarının yaygın olarak görüldüğü yağıșlı bölgelerimizde genellikle CR ve küllemeye dayanıklı pancar çeşitleri tercih edilirken, fiyat belirlemede polar şeker miktarı dikkate alındığından ülke genelinde çiftçi ve şeker şirketlerinin anlaştığı $\mathrm{N}$ tipi ön planda olmak üzere NZ ve Z tipleri de üretilmeye başlanmıştır.

Şeker pancarı bitkisi yeterli nem ve sıcaklık koşullarının sağlanması halinde vejetasyon periyodu süresince gelişmeye devam edebilmektedir [2]. Pancar kök-gövdesindeki kuru madde gelişme mevsimi ilerledikçe artış göstermekte, şeker oranı \%20-25'e kadar çlkabilmektedir [3]. Bu nedenle şeker pancarının hasat zamanı kök-gövde gelişimininim yeterince oluştuğu dönemde başlamakta, fabrikanın üretim sezonu, erken söküm isteği, iklim şartları, üreticinin iş ve ekipman gücü, kendinden sonra gelecek bitkinin ekim zamanı dikkate alınarak Eylül ayından başlamak üzere 2-3 aylık bir periyotta yapılmaktadır.

Bu çalışmada; birim alan kök-gövde verimi ile şeker oranını optimize edecek farklı tiplerdeki pancar çeşitlerinin bölgedeki uyum yetenekleri (çeşit $x$ çevre etkileşimleri) ve bu çeşitlerin optimum şeker üretimi için en uygun hasat zamanlarının belirlenmesi amaçlanmıștır.

\section{Materyal ve Metot}

Bu araștırma, 2012 ve 2013 üretim sezonunda Süleyman Demirel Üniversitesi Tarımsal Araştırma ve Uygulama Merkezi deneme alanlarında yürütülmüştür. Denemede KWS Türk Tarım A.Ş. firmasından temin edilen genetik monogerm özellikteki Aranka ve Espernaza (N tipi), Sandrina ve Esperia (NZ tipi), Felicita ve Agnessa ( $\mathrm{Z}$ tipi) ile bölgede yetiştiriciliği gerçekleştirilen Begonia (N tipi) şeker pancarı çeşitleri olmak üzere toplam 7 çeşit materyal olarak kullanılmıştır.

Denemeler her iki yılda da toprak özellikleri benzer alanlarda kurulmuş olup, deneme tarlası toprağı; tekstür bakımından tınlı, pH 8.2, toplam tuz içeriği $\% 0,025$ ve katyon değişim kapasitesi \% 36, kireççe zengin $(\% 25,5)$, organik madde miktarı bakımından fakir (\%1,3) (Walcley-Black metoduna göre), alınabilir fosfor $\left(16.8 \mathrm{mg} / \mathrm{kg} \mathrm{P}_{2} \mathrm{O}_{5}\right)$ bakımından fakir, potasyum bakımından zengin (179 kg/da K20)'dir.

Araştırmanın yapıldığı 2012 ve 2013 yıllarında ortalama sıcaklık uzun yıllar ortalamasına göre daha yüksek olmuștur. Deneme yıllarındaki ortalama nispi nemin uzun yıllar ortalamasına benzer olduğu görülmüștür. Vejetasyon döneminde düşen yağış miktarı çalışmanın ilk yılında (295.2 mm) uzun yıllar ortalamasından (261.1 mm) yüksek, ikinci yılında ise (269.4 mm) benzer olmuştur. Yağış miktarının üretim sezonundaki aylara göre değişimi incelendiğinde, 2013 yılı aylık yağış değişimi, uzun yıllar ortalamasına paralellik gösterirken, 2012 yılında Mayıs ayında uzun yıllar ortalaması ve 2013 yılına göre yaklaşık iki kat fazla yağış meydana gelmiştir. Haziran ayında ise 2012 yılında uzun yıllar ortalaması ve 2013 yılına göre daha az yağış meydana gelmiştir (Tablo 1).

\subsection{Yöntem}

Çalışma, her iki yılda da Tesadüf Blokları Deneme planında faktöriyel denem desenine göre 3 tekerrürlü olarak kurulmuştur. Çalışmada birinci faktör olarak şeker pancarı çeşitleri, ikinci faktör olarak da hasat zamanları (çıkıştan 140, 155, 170, 185 ve 200 gün sonra) ele alınmıştır.

Tablo 1. Deneme yılları ve uzun yıllar ortalaması iklim verileri

\begin{tabular}{|c|c|c|c|c|c|c|c|c|c|}
\hline \multirow{2}{*}{ Aylar } & \multicolumn{3}{|c|}{$\begin{array}{c}\text { Ortalama } \\
\text { Sicaklık }\left({ }^{\circ} \mathrm{C}\right)\end{array}$} & \multicolumn{3}{|c|}{$\begin{array}{c}\text { Ortalama } \\
\text { Nispi nem (\%) }\end{array}$} & \multicolumn{3}{|c|}{$\begin{array}{c}\text { Toplam } \\
\text { Yağış }(\mathrm{mm})\end{array}$} \\
\hline & $\begin{array}{l}\text { Uzun } \\
\text { yıllar }\end{array}$ & 2012 & 2013 & $\begin{array}{l}\text { Uzun } \\
\text { yillar }\end{array}$ & 2012 & 2013 & $\begin{array}{l}\text { Uzun } \\
\text { yillar }\end{array}$ & 2012 & 2013 \\
\hline Nisan & 10.7 & 11.7 & 11.7 & 61.3 & 55.2 & 56.5 & 56.2 & 53.2 & 53.3 \\
\hline Mayıs & 15.6 & 14.5 & 15.1 & 57.4 & 64.0 & 50.4 & 50.4 & 107.4 & 55.7 \\
\hline Haziran & 20.2 & 22.4 & 20.0 & 51.2 & 43.6 & 47.4 & 29.6 & 18.1 & 33.2 \\
\hline Temmuz & 23.6 & 25.4 & 24.5 & 45.4 & 39.7 & 41.5 & 14.9 & 0.8 & 13.7 \\
\hline Agustos & 23.2 & 22.8 & 24.9 & 46.4 & 41.4 & 39.1 & 10.5 & 34.6 & 12.1 \\
\hline Eylül & 18.6 & 20.2 & 18.4 & 51.9 & 43.8 & 43.3 & 15.4 & 16.4 & 18.6 \\
\hline Ekim & 12.9 & 14.6 & 12.9 & 62.0 & 65.1 & 54.0 & 37.6 & 38.8 & 37.7 \\
\hline Kasım & 7.4 & 9.1 & 6.8 & 68.5 & 70.6 & 65.5 & 46.5 & 25.9 & 45.2 \\
\hline Toplam & 15.6 & 17.6 & 16.8 & 55.5 & 53.0 & 55.4 & 261.1 & 295.2 & 269.4 \\
\hline
\end{tabular}

Değerler Devlet Meteoroloji Müdürlüğü'nden alınmıștır. 
Ekimler, her iki yılda da Nisan ayının ilk haftasında (5-6 Nisan), $10 \mathrm{~cm}$ sıra üzeri ve $45 \mathrm{~cm}$ sıra arası olacak şekilde el ile yapılmıştır. Denemede her parsel $6 \mathrm{~m}$ uzunluğunda toplam 4 sıradan oluşmuştur. Çalışma her blokta 7 çeşit x 5 hasat zamanı olmak üzere 35 parsel, toplamda ise 105 parsel olarak kurulmuştur. Bloklar arasında $2 \mathrm{~m}$ boşluk bırakılarak yapılan ekimler için toplamda $1365 \mathrm{~m}^{2}$ (blok uzunluğu $65 \mathrm{~m}$ x blok eni $21 \mathrm{~m}$ )'lik bir alan kullanılmıştır. Çalışmada saf $15 \mathrm{~kg} / \mathrm{da}$ azot ve 10 $\mathrm{kg} /$ da fosfor olacak şekilde gübreleme yapılmıştır [4].

Fosforun tamamı ve azotlu gübrenin yarısı ekimle beraber Diamonyum fosfat (DAP \%18 N \% $46 \mathrm{P}_{2} \mathrm{O}_{5}$ ) ve amonyum sülfat (\% $21 \mathrm{~N}$ ) formunda verilmiştir. Azotun kalan kısmı ise ilk çapa ile beraber amonyum nitrat ( $\left.\begin{array}{lll}\% & 33 & \mathrm{~N}\end{array}\right)$ formunda uygulanmıştır. Su stresinden dolayı bitkilerde renk koyu yeşile dönmeye başladığında yağmurlama sulama yöntemi ile sulama yapılmıştır. Denemenin ilk yılında 8, ikinci yılında ise 9 defa sulama işlemi yapılmıştır. Bitkilerin 3-6 yapraklı olduğu rozet döneminde ilk çapa yapılmış, ilk çapalama ile birlikte sıra üzeri mesafe 20-25 cm olacak şekilde seyreltme işlemi gerçekleştirilmiştir. Yabancı ot yoğunluğuna bağlı olarak 2-3 kez el ile yabancl ot mücadelesi yapılmıştır.

Pancar hasat zamanları, Burdur Seker Fabrikasının pancar hasat süresi (170 gün) ve erken söküm dikkate alınarak belirlenmiştir. Buna göre ilk bitki hasatları çıkışların tamamlanmasından 140 gün sonra başlamış; 1-6 Eylül (140), 15-20 Eylül (155), 1-6 Ekim (170), 15-20 Ekim (185) ve 1-6 Kasım (200) olmak üzere 5 farklı zamanda her parselin ortasındaki iki sıra pancar çatalı kullanılarak hasat edilmiştir.

Ölçüm ve analizler sonucu elde edilen veriler SAS (2009) istatistik paket programında GLM prosedürü kullanılarak standart varyans analizi tekniğinde (ANOVA) analiz edilmiş ve ortalamalar arasındaki farklılıklar LSD çoklu karşılaştırma testine göre belirlenmiștir.

\section{Bulgular}

Çalışmada, 2012 ve 2013 yetiştirme sezonları arasındaki farklılık istatiksel olarak önemsiz bulunmuştur (Tablo 2). Bulguların açılklanmasında iki yıllık ortalama veriler kullanılmıştır.

Kök-Gövde Verimi: Çeşitlerin ortalama kök-gövde verimleri 6731 ile $8860 \mathrm{~kg} / \mathrm{da}$ arasında geniş bir değişim göstermiştir. NZ tipinde olan Esperia (8860 $\mathrm{kg} / \mathrm{da}$ ) ile $\mathrm{N}$ tipinde olan Aranka (8834 kg/da) ve Esperanza (8758 kg/da) çeşitleri aynı istatistiki grupta yer alarak en yüksek ortalama dekara kökgövde verimine sahip olmuşlardır. En düşük kökgövde verimi ise $\mathrm{Z}$ tipinde olan Felicita $(6731 \mathrm{~kg} / \mathrm{da})$ çeşidinde belirlenmiştir (Tablo 3).

Tablo 2. Farklı zamanlarda hasat edilen şeker pancarı çeşitlerinin bazı verim unsurları ve kalite kriterleri ile ilgili varyans analiz tablosu

\begin{tabular}{|c|c|c|c|c|c|c|}
\hline $\begin{array}{l}\text { Varyasyon } \\
\text { Kaynakları }\end{array}$ & SD & $\begin{array}{l}\text { Dekara Kök- } \\
\text { gövde Verimi }\end{array}$ & $\begin{array}{c}\text { Dekara } \\
\text { Biyolojik Verim }\end{array}$ & $\alpha$-Amino Azot & Polar Şeker & $\begin{array}{l}\text { Dekara Polar } \\
\text { Şeker Verimi }\end{array}$ \\
\hline Yil (Y) & 1 & 0.70 & 1.80 & 0.04 & 1.97 & 0.01 \\
\hline Blok(Yıl) & 4 & 2.52 & 0.91 & 0.58 & 1.97 & 2.23 \\
\hline Çeşit (Ç) & 6 & $129 * *$ & $188^{* *}$ & $681^{* *}$ & $213^{* *}$ & $32.5^{* *}$ \\
\hline $\mathbf{Y x C}$ & 6 & 0.44 & 0.25 & 1.06 & 0.77 & 0.41 \\
\hline Söküm Zamanı (S) & 4 & $150^{* *}$ & $5.58^{* *}$ & $5112^{* *}$ & $130^{* *}$ & $214^{* *}$ \\
\hline $\mathbf{Y} \times \mathbf{S}$ & 4 & 0.03 & 0.06 & 1.09 & $3.17^{*}$ & 0.59 \\
\hline $\mathrm{C} \times \mathrm{S}$ & 24 & $4.16^{* *}$ & $6.43^{* *}$ & $106^{* *}$ & $11.20^{* *}$ & $3.87^{* *}$ \\
\hline C $\times S \times Y$ & 25 & 0.03 & 0.08 & 1.33 & 1.14 & 0.17 \\
\hline Hata & 136 & & & & & \\
\hline VK (\%) & & 4.95 & 4.10 & 3.48 & 2.35 & 5.76 \\
\hline
\end{tabular}

Tablo 3. Değișik zamanlarda hasat edilen șeker pancarı çeșitlerinin dekara kök-gövde verimleri (kg)

\begin{tabular}{ccccccccc}
\hline $\begin{array}{c}\text { Çeşit/ } \\
\text { Söküm } \\
\text { zamanı }\end{array}$ & Aranka & Esperanza & Sandrina & Esperia & Felicita & Agnessa & Begonia & Ortalama \\
\hline $\mathbf{1 4 0}$ & 8396 & 7612 & 7557 & 7451 & 6007 & 6139 & 6348 & $7073 \mathrm{~d}$ \\
$\mathbf{1 5 5}$ & 8605 & 8110 & 8277 & 8174 & 6446 & 6907 & 7092 & $7659 \mathrm{c}$ \\
$\mathbf{1 7 0}$ & 8823 & 8984 & 8973 & 8762 & 6761 & 7752 & 7965 & $8289 \mathrm{~b}$ \\
$\mathbf{1 8 5}$ & 9073 & 9482 & 9037 & 9820 & 7110 & 8024 & 8612 & $8737 \mathrm{a}$ \\
$\mathbf{2 0 0}$ & 9273 & 9602 & 9084 & 10096 & 7332 & 8155 & 9064 & $8887 \mathrm{a}$ \\
\hline Ortalama & $8834 \mathrm{a}$ & $8758 \mathrm{a}$ & $8506 \mathrm{~b}$ & $8860 \mathrm{a}$ & $6731 \mathrm{e}$ & $7396 \mathrm{~d}$ & $7816 \mathrm{c}$ & \\
\hline
\end{tabular}

Lsd ç x s : 460 
Hasat zamanının gecikmesi ile birlikte çeşitlerin ortalama kök-gövde verimleri artıș göstermiștir. Çıkıștan 140 gün sonra ortalama $7073 \mathrm{~kg} /$ da olarak belirlenen kök-gövde verimi son hasat zamanında (çıkıştan 200 gün sonra) yaklaşık \%25 oranında artarak 8887 kg/da'a yükselmiştir (Tablo 3). Hasadın gecikmesi ile birlikte kök veriminde gerçekleșen artış oranları, ilk hasattan son hasada doğru sırasıyla $\% 6,7, \% 8,2, \% 5,2$ ve $\% 2,6$ olarak gerçekleşmiştir.

Çeșitlerin kök-gövde verimleri hasat zamanına bağlı olarak önemli varyasyonlar göstermiştir. Aranka, Esperanza, Begonia, Sandrina ve Agnessa çeşitlerinin kök-gövde verimleri 170. günden sonra yapılan hasatlarda istatistiki açıdan önemli bir değişim göstermezken, Esperia ve Felicita çeşitlerinde ise en yüksek kök-gövde verimleri 185. günden sonra yapılan hasatlarda belirlenmiştir (Tablo 3). Esperia ve Begonia çeşitlerinin kök-gövde verimlerinde hasat zamanı boyunca meydana gelen artış miktarı (2500 kg/da'dan fazla) diğer çeşitlerden daha yüksek olurken, en düşük artış Aranka çeșidinde (900 kg/da) ortaya çıkmıştır (Tablo 3).

Dekara Biyolojik Verim: Araștırmada kullanılan çeșitlerden Sandrina (11641 kg/da), Aranka (11549 $\mathrm{kg} / \mathrm{da}$ ) ve Esperanza (11430kg/da) aynı istatistiki grupta yer alarak en yüksek biyolojik verime sahip olurken, en düşük biyolojik verim Felicita (8912 $\mathrm{kg} / \mathrm{da}$ ) çeşidinde belirlenmiştir (Tablo 4).

Hasat zamanının biyolojik verim üzerine etkisi değişken olmuş, ilk hasattan 170. güne kadar yapılan hasatlarda ortalama biyolojik verim (10768-10632 $\mathrm{kg} / \mathrm{da}$ ) dalgalanma göstermekle birlikte meydana gelen değişimler istatistiki anlamda önemsiz çıkmış, son hasat zamanında ortalama biyolojik verim (10357 kg/da) ise önemli derecede azalma göstermiştir (Tablo 4).
Çeşitlerin biyolojik verimleri hasat zamanına bağlı olarak önemli düzeyde değişiklik göstermiştir. Aranka ve Felicita çeşitleri çııștan 140 gün, Sandirna çeşidi 170 gün, Begonia çeşidi ise 185 gün sonra en yüksek biyolojik verim değerine ulaşmıştır. Esperanza ve Agnessa çeşitlerinde ise hasat zamanının biyolojik verim üzerine önemli bir etkisi olmamıştır (Tablo 4).

$\boldsymbol{\alpha}$-Amino Azot Miktarı: Çeşitlerin ortalama $\alpha$-amino azot içerikleri 3.45 -ile $5.23 \mathrm{mmol} / 100 \mathrm{~g}$ arasında geniş bir değişim göstermiştir. Çeşitlerin arasında en yüksek $\alpha$-amino azot içeriği Z tipinde olan Agnessa (5.23 mmol/100g) çeşidinde belirlenirken, bunu sırası ile N tipindeki Begonia (4.88mmol/100 g) ve yine $\mathrm{Z}$ tipindeki Falicita $(4.39 \mathrm{mmol} / 100 \mathrm{~g})$ çeşitleri takip etmiştir. En düşük $\alpha$-amino azot miktarı ise Esperanza ve Esperia çeşitlerinde (sırasıyla 3.45 ve $3.48 \mathrm{mmol} / 100 \mathrm{~g}$ ) tespit edilmiştir (Tablo 5).

Çalışmada kullanılan tüm çeşitlerde $\alpha$-amino azot içeriği hasat zamanın ilerlemesi ile birlikte önemli oranlarda azalma göstermiştir. Çeşitlerin ilk ve son hasat zamanları arasında $\alpha$-amino azot içeriklerinde meydana gelen azalma miktarı oransal olarak farklılık göstermiş, çıkıştan 140 gün sonra yapılan hasatlarda çeşitlerin ortalama $\alpha$-amino azot içerikleri 5.68-9.02 mmol/100g arasında değişim gösterirken, son hasat zamanında çeşitler arasındaki farklılık (2.05-3.94 mmol/100g) önemli ölçüde azalmıştır (Tablo 5). Agnessa çeşidinin a $\alpha$-amino azot içeriği ilk ve son hasat zamanları arasında

\%70'den fazla azalma gösterirken, bu azalma Begonia çeşidinde \%37 oranında olmuş, diğer eşitlerde ise \%51-66 arasında gerçekleşmiştir (Tablo 5). Çeşitler arasındaki azalma oranının zamana göre farklılık sergilemesi çeşit $\mathrm{x}$ hasat zamanı interaksiyonunun önemli olmasında etkili olmuştur.

Tablo 4. Hasat zamanına bağlı olarak șeker pancarı çeșitlerinin dekara biyolojik verimleri (kg)

\begin{tabular}{|c|c|c|c|c|c|c|c|c|}
\hline $\begin{array}{l}\text { Çeşit/ } \\
\text { Söküm } \\
\text { zamanı }\end{array}$ & Aranka & Esperanza & Sandrina & Esperia & Felicita & Agnessa & Begonia & Ortalama \\
\hline 140 & 12544 & 11750 & 12304 & 10451 & 9369 & 9482 & 9482 & $10768 \mathrm{a}$ \\
\hline 155 & 12038 & 11419 & 11444 & 10540 & 9132 & 9362 & 9696 & $10672 \mathrm{ab}$ \\
\hline 170 & 11518 & 11479 & 11685 & 11196 & 8868 & 9934 & 10029 & $10632 \mathrm{ab}$ \\
\hline 185 & 11072 & 11355 & 11590 & 11536 & 8629 & 9917 & 10330 & 10518 bc \\
\hline 200 & 10572 & 11153 & 11183 & 11354 & 8562 & 9438 & 10237 & $10357 \mathrm{c}$ \\
\hline Ortalama & $11549 \mathrm{a}$ & $11430 a$ & $11641 \mathrm{a}$ & $11016 \mathrm{~b}$ & $8912 \mathrm{e}$ & $9627 \mathrm{~d}$ & $9955 \mathrm{c}$ & \\
\hline
\end{tabular}

Lsd ç x s :496

Tablo 5. Hasat zamanına bağlı olarak șeker pancarı çeșitlerinin $\alpha$-amino azot miktarı (mmol/100 g)

\begin{tabular}{|c|c|c|c|c|c|c|c|c|}
\hline $\begin{array}{c}\text { Çeşit/ } \\
\text { Söküm } \\
\text { zamanı }\end{array}$ & Aranka & Esperanza & Sandrina & Esperia & Felicita & Agnessa & Begonia & Ortalama \\
\hline 140 & 5.68 & 5.99 & 6.52 & 5.87 & 7.30 & 9.02 & 6.31 & $6.67 \mathrm{a}$ \\
\hline 155 & 3.95 & 3.83 & 4.81 & 3.69 & 5.14 & 6.49 & 5.43 & $4.76 \mathrm{~b}$ \\
\hline 170 & 3.26 & 2.87 & 3.76 & 3.01 & 4.74 & 4.72 & 4.48 & $3.83 c$ \\
\hline 185 & 2.92 & 2.43 & 3.37 & 2.80 & 2.43 & 3.61 & 4.23 & $3.12 \mathrm{~d}$ \\
\hline 200 & 2.67 & 2.11 & 2.55 & 2.05 & 2.36 & 2.33 & 3.94 & $2.57 \mathrm{e}$ \\
\hline Ortalama & $3.70 \mathrm{e}$ & $3.45 \mathrm{f}$ & $4.20 \mathrm{~d}$ & $3.48 \mathrm{f}$ & $4.39 \mathrm{c}$ & $5.23 \mathrm{a}$ & $4.88 \mathrm{~b}$ & \\
\hline
\end{tabular}


Polar Şeker Oranı: Çeşitlerin ortalama polar şeker oranları tiplere bağlı olarak değişim göstermiş, şeker tipi (Z tipi) olan Felicita $(\% 21,16)$ en yüksek polar şeker oranına sahipken, bunu yine şeker tipinde olan Agnessa $(\% 20,85)$ çeşidi takip etmiştir. Normal (N tipi) tipte olan Aranka $(\% 18,35)$ ve Espranza $(\% 18,09)$ çeşitlerinin polar şeker oranları daha düşük olarak belirlenmiştir (Tablo 6).

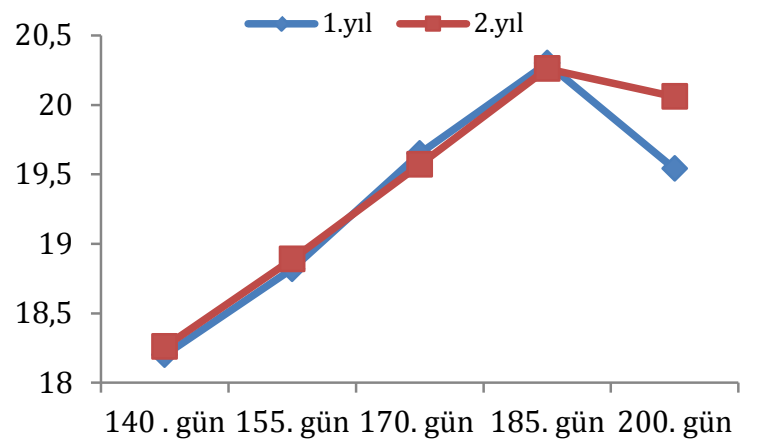

Şekil 1. Söküm zamanı ve yıllara bağlı olarak polar şeker oranındaki değişim

Hasat zamanlarının ortalama polar şeker oranı üzerine etkisi çok önemli olmuş, ilk hasat zamanında $\% 18,27$ olan ortalama polar şeker oranları 185. güne kadar lineer olarak artış göstermiş ve \%20,28'e yükselmiștir. Son hasat zamanı olan 200. günde ise polar şeker oranı önemli derecede azalmıș ve \%19,80 seviyesine düșmüștür (Tablo 6).

Dekara Polar Şeker Verimi: Çalışmada en yüksek polar şeker verimi NZ tipi pancar grubunda yer alan Esperia $(1674 \mathrm{~kg} / \mathrm{da})$ çeșidinde belirlenmiş, bunu aynı tipte olan Sandrina (1664 kg/da) çeşidi takip etmiştir. Z tipindeki Felicita $(1429 \mathrm{~kg} / \mathrm{da})$ çeşidi ile N tipindeki Begonia (1469 kg/da) çeşitleri aynı istatistiki grupta yer alarak en düşük polar şeker verimine sahip olan çeşitler olmuştur (Tablo 7).

Polar şeker verimi hasat zamanının ilerlemesi ile birlikte önemli derecede artış göstermiş, çıkıştan 140 gün sonra $1289 \mathrm{~kg} / \mathrm{da}$ olarak belirlenen ortalama polar şeker verimi, çıkıştan sonra 185 . ve 200. günlerde yapılan hasatlarda sırası ile 1760 $\mathrm{kg} /$ da ve $1750 \mathrm{~kg} /$ da seviyesine ulaşmıştır (Tablo 7).

Çeşitlerin hasat zamanına bağlı olarak polar şeker verimleri önemli değişimler göstermiştir. Aranka, Esperanza ve Sandrina çeşitlerinde polar şeker verimleri hasat zamanının ilerlemesi ile beraber artmış, bu artış 185. günden sonra yapılan hasatlarda istatistiki açıdan önemsiz bulunmuştur. Esperia, Felicita, ve Begonia çeşitlerinde polar şeker verimi 185. güne kadar artmış, daha sonra ise azalma eğiliminde olmuştur. Esperia ve Agnessa çeşitlerinde en yüksek polar şeker verimleri (sırası ile $1898 \mathrm{~kg} /$ da ve $1859 \mathrm{~kg} /$ da) çıkıştan 185 gün sonra yapılan hasatlarda, tespit edilmiştir (Tablo 7).

\section{Tartışma ve Sonuç}

Kök-Gövde Verimi: Çeşitler arasında birim alanda kök-gövde verimi bakımından tespit edilen farklılıkların çeşitlerin genetik potansiyellerinden ve bölge şartlarına uyum yeteneklerinin farklı olmasından ileri geldiği düşünülmektedir. Nitekim çalışmada verim tipinde olan ( $\mathrm{N}$ ve NZ tipi) çeşitlerin şeker tipinde (Z tipi) olanlardan daha yüksek kökgövde verimine sahip olmaları, genetik yapının kökgövde verimine olan etkisini açıçca ortaya koymaktadır. Bulgularımız, diğer araștırmacıların bulgularıyla benzerlik göstermiș ve şeker pancarı çeşitlerinin kök-gövde verimleri arasında önemli farklılıklar olduğu belirlenmiştir [2, 5-7].

Tablo 6. Hasat zamanına bağlı olarak şeker pancarı çeşitlerinin polar şeker oranları (\%)

\begin{tabular}{ccccccccc}
\hline $\begin{array}{c}\text { Ceșit/ } \\
\text { Söküm } \\
\text { zamanı }\end{array}$ & Aranka & Esperanza & Sandrina & Esperia & Felicita & Agnessa & Begonia & Ortalama \\
\hline $\mathbf{1 4 0}$ & 17.74 & 17.80 & 18.21 & 18.16 & 19.70 & 18.73 & 17.56 & $18.27 \mathrm{~d}$ \\
$\mathbf{1 5 5}$ & 17.84 & 18.00 & 18.96 & 18.98 & 20.59 & 19.28 & 18.31 & $18.85 \mathrm{c}$ \\
$\mathbf{1 7 0}$ & 18.23 & 18.11 & 19.65 & 19.39 & 21.43 & 21.81 & 18.62 & $19.61 \mathrm{~b}$ \\
$\mathbf{1 8 5}$ & 18.77 & 18.23 & 20.27 & 19.33 & 22.49 & 23.18 & 19.70 & $20.28 \mathrm{a}$ \\
$\mathbf{2 0 0}$ & 19.15 & 18.29 & 20.48 & 18.52 & 21.58 & 21.25 & 19.32 & $19.80 \mathrm{~b}$ \\
\hline Ortalama & $18.35 \mathrm{e}$ & $18.09 \mathrm{f}$ & $19.51 \mathrm{c}$ & $18.87 \mathrm{~d}$ & $21.16 \mathrm{a}$ & $20.85 \mathrm{~b}$ & $18.70 \mathrm{~d}$ & \\
\hline
\end{tabular}

Lsd ç X s :0.57

Tablo 7. Farklı zamanlarda hasat edilen șeker pancarları çeșitlerinin dekara polar șeker verimleri (kg)

\begin{tabular}{ccccccccc}
\hline $\begin{array}{c}\text { Çeșit/ } \\
\begin{array}{c}\text { Söküm } \\
\text { zamanı }\end{array}\end{array}$ & Aranka & Esperanza & Sandrina & Esperia & Felicita & Agnessa & Begonia & Ortalama \\
\hline $\mathbf{1 4 0}$ & 1490 & 1355 & 1376 & 1353 & 1184 & 1149 & 1114 & $1289 \mathrm{~d}$ \\
$\mathbf{1 5 5}$ & 1535 & 1459 & 1569 & 1552 & 1327 & 1332 & 1299 & $1439 \mathrm{c}$ \\
$\mathbf{1 7 0}$ & 1609 & 1627 & 1763 & 1699 & 1449 & 1693 & 1486 & $1618 \mathrm{~b}$ \\
$\mathbf{1 8 5}$ & 1703 & 1729 & 1831 & 1898 & 1599 & 1859 & 1697 & $1760 \mathrm{a}$ \\
$\mathbf{2 0 0}$ & 1776 & 1757 & 1780 & 1867 & 1584 & 1731 & 1751 & $1761 \mathrm{a}$ \\
\hline Ortalama & $1623 \mathrm{bc}$ & $1585 \mathrm{dc}$ & $1663 \mathrm{a}$ & $1674 \mathrm{a}$ & $1429 \mathrm{e}$ & $1553 \mathrm{~d}$ & $1469 \mathrm{e}$ & \\
\hline
\end{tabular}

Lsd ç x : 103 
Hasadın gecikmesi ile birlikte daha uzun süre toprakta kalan bitkiler su ve besin maddelerinden daha fazla faydalanmakta ve buna bağlı olarak kökgövde verimleri artmaktadır. Buna ilave olarak, vejetasyon süresinin uzaması, bitkilerin güneş enerjisinden daha fazla faydalanmalarına ve daha fazla besin maddesi depolamalarina neden olmaktadır. Farklı lokasyon ve iklim tiplerinde yapılan çalışmalarda kısa vejetasyon periyodunda yetiştirilen şeker pancarlarında kök-gövde veriminin azaldığı araştırmacılar tarafından bildirilmiștir [811]. Son hasatlarda gerçekleşen kök-gövde verimindeki artışın düşük olması, bu hasatların yapıldığı aylarda toplam solar radyasyon miktarının azalması ve gece gündüz sıcaklık farkının artmasına bağlı olarak bitkilerin daha az günlük fotosentez yapması ile açıklanabilir. Nitekim, şeker pancarı kanopisinin ışığa tepki eğrisinin Eylül ayına kadar sabit olduğu, daha sonra ise azaldığını bildirilmiştir [12]. Bulgularımız, hasadın gecikmesi ile birlikte şeker pancarında kök veriminin arttığını ve geciken hasatta kök veriminde gerçekleșen artıșın daha düşük olduğunu bildiren araştırmacıların bulguları ile uyum göstermektedir [13-16].

$\boldsymbol{\alpha}$-Amino Azot Miktarı: Şeker pancarı köklerinde bulunan $\alpha$-amino azot, şeker içeriğinde azalmaya molasigenetik faktörün neden olduğu kabul edilmektedir [17]. $\alpha$-amino azot, şeker pancarı bitkisinde yeniden kullanılmak üzere biriktirilen azotun organik bir formu olup [18], kök-gövdede $\alpha$ amino azot miktarının artması, önemli miktarda şekerin melasa bağlamasına neden olarak fabrikasyon sürecinde elde edilebilir şeker miktarını azaltmaktadır. Şeker pancarı kök-gövdesindeki kabul edilebilir $\alpha$-amino azot miktarının mineral topraklarda $2.14 \mathrm{mmol} / 100 \mathrm{~g}$, organik topraklarda ise $2.86 \mathrm{mmol} / 100 \mathrm{~g}$ olduğu daha önceki çalışmalar ile belirlenmiştir [17]. Çalışmamızda kullanılan çeşitlerin özellikle son hasat zamanında belirtilen $\alpha$ amino azot değerlerine yakın olduğu, daha önce yapılan hasatlarda ise $\alpha$-amino azot içeriklerinin literatürde verilen değerlerden yüksek olduğu kaydedilmiştir [10,13].

Şeker pancarında, $\alpha$-amino azot içeriğini etkileyen faktörlerden bazıları başta azotlu gübreleme olmak üzere çeşit, iklim ile toprak şartları ve pancar olgunluğu olarak bilinmektedir [19]. Şeker pancarı çeşitlerinde $\alpha$-amino azot içeriği çeşitlere göre farklılı göstermektedir [20]. Farklı şeker pancarı çeşitleri kullanarak yürütülen bir çalışmada, $\alpha$-amino azot içeriğinin $1.72-8.50 \mathrm{mmol} / 100 \mathrm{~g}$ arasında değiștiği bildirilmiștir [21]. Çıkıştan sonra 140. güne tekabül eden Eylül ayının ilk haftalarında iklim koşullarına da bağlı olarak, şeker pancarında bitki gelişimi daha hızlı olmaktadır. Bu durum bitkilerin bu dönemde başta azot olmak üzere topraktan kaldırdıkları besin maddelerinin daha yüksek olduğunu göstermektedir. Çalışmada erken hasatlarda $\alpha$-amino azot içeriğinin çok yüksek olması bahsedilen dönemde sıcaklığın da etkisi ile (yüksek fotosentez hızına bağlı olarak) yüksek metabolik aktiviteye sahip olan pancar bitkilerinin topraktan azot alınımına devam etmesi ile açıklanabilir. Vejetasyon döneminin uzaması ile birlikte toprak kullanılabilir azot miktarının azaldığı, bitkinin ihtiyaç duyduğu azotun ise büyük ölçüde depoladığı $\alpha$-amino azot ile karşılandığı düşünülmektedir. Konu ile ilgili olarak, şeker pancarında Ekim ayında yapılan hasatlarda Eylül ayına göre $\alpha$-amino azot içeriğinin \%18.6 oranında azaldığını bazı araștırmacılar tarafından da bildirilmiștir [22].

Polar Şeker Oranı: Çalışmada kullanılan çeşitlerden Z tipindeki çeşitlerin daha yüksek polar şeker oranına sahip olması, şeker içeriğinin önemli bir kalıtsal özellik olduğunu göstermektedir. Farklı lokasyonlarda, değişik pancar çeşitleri ile yapılan araştırmalarda çeşitlerin şeker içeriklerinin önemli varyasyonlar gösterdiği birçok araştırmacı tarafından da bildirilmiştir [23-27].

Pancar kök-gövdesindeki şeker konsantrasyonu çeșide, bitki sıklığına, iklim ve toprak koşullarına, gübrelemeye, vejetasyon süresine, hasat zamanı ile hastalık ve zararlı popülasyonuna bağlı olarak önemli değişiklikler göstermektedir [27]. Gecegündüz arasındaki sıcaklık farkının artması ve daha uzun vejetasyon koşulları polar şeker oranını arttırıcı etkide bulunmaktadır. Çalışmamızda da gece sıcaklıklarının azalmaya başladı̆̆ Ekim-Kasım aylarına denk gelen hasat zamanlarında (170-185. günler) polar şeker oranı değerleri artış göstermiştir. Bununla birlikte, son hasat zamanı olan 200. günde bazı çeşitlerde polar şeker oranında belirlenen azalmanın bu dönemde bahsedilen çeşitlerin yaprak miktarlarının \%60'dan fazla azalmasından kaynaklandığı düşünülmektedir. Yaprak miktarı azalan pancarlarda solunum (respirasyon) için gerekli enerjinin fotosentez ile karşılanamadığı ve kök-gövdede depo edilen şekerlerin yıkımı başlandığından polar şeker oranının azaldığ düşünülmektedir. Yapılan çalışmalarda, birçok araştırıcı hasat zamanının gecikmesi ile birlikte polar șeker oranın arttı̆̆ını bildirilmiștir [28-31]. Buna ilave olarak, geç yapılan ve buna bağlı olarak da kısa vejetasyon periyodunda yetişen şeker pancarlarında, polar şeker oranı ile beyaz şeker oranı ve veriminin azaldığı birçok araştırmacı tarafından bildirilmiştir [32-35].

Dekara Polar Şeker Verimi: Araştırmada çeşitlerin polar şeker verimleri kök-gövde verimleri ile polar şeker oranları kullanılarak hesaplanmıştır. Çeşitlerin hasat zamanlarına da bağlı olarak polar şeker verimlerinde tespit edilen farklılıklar, kök-gövde verimleri ile polar şeker oranlarında belirlenen farklılıklarla paralellik göstermiştir. Bu nedenle, hem kök-gövde verimi hem de polar şeker oranı yüksek olan çeşitlerde polar şeker verimleri de yüksek olarak tespit edilmiştir. Çalışmada Esperia, Felicita ve Agnessa çeşitlerinde polar şeker oranlarının 185. günden sonra önemli derecede azalması (Tablo 7), 
bu çeşitlerde polar şeker verimlerinin de azalmasına neden olmuştur. Bulgularımıza benzer olarak, șeker pancarında hasadın Kasım sonuna kadar geciktirilmesinin kök-gövde ve şeker verimi ile şeker oranını azalttığı Brown [36] tarafından bildirilmiştir.

Sonuç olarak; Şeker pancarı hasat zamanın belirlenmesinde kullanılan çeşidin büyük önem taşıdığı ve çeşitlerin şeker verimleri dikkate alınarak hasat zamanlarının belirlenmesi gerektiği anlaşılmıştır. Isparta koşullarında yapılacak üretimlerde Aranka ve Begonia çeșitlerinin 200 gün, diğer çeşitlerin ise 185 günlük vejetasyon süresini doldurmaları gerektiği sonucuna varılmıştır. Eylül başı sökümünde Aranka, Ekim başı sökümünde Sandrina, Kasım başı sökümünde ise Sandrina ve Esperia çeşitleri ön plana çıkmıştır. Buna göre erken söküm yapılacak bölgelere Aranka ve Sandrina, geç söküm yapılacak bölgelere ise Esperia ve Sanrinda çeşitlerinin önerilmesinin yerinde olacağı sonucuna varılmıștır.

\section{Teşekkür}

3397-YL1-12 No`lu proje ile Yüksek Lisans tezimi maddi olarak destekleyen Süleyman Demirel Üniversitesi Bilimsel Araștırma Projeleri Yönetim Birimi Başkanlığı'na teşekkür ederim.

\section{Kaynakça}

[1] Er, C.. Uranbey, S., 1998. Nişasta Şeker Bitkileri. Ankara Ziraat Fakültesi Yayınları No:1504. 334s. Ankara.

[2] Jozefyova, L., Pulkrabek, J., Urbam, J. 2004. Effect of Harvest Time on Sugar Beet Fertilised with ;Increased Nitrogen. Science and Technology. 2. 232-237.

[3] Heidari, G., Sohrabi, Y., 2008. Influence of Withholding Irrigation nd Harvest Times on Yield and Quality of Sugar Beet (Beta vulgaris). International Journal of Agriculture and Biology. 10(4). 427-431.

[4] Karadoğan, T., Kurtçepe, Ş., 2005. Göller Yöresine Uygun Şeker Pancarı Çeşitlerinin Belirlenmesi. Türkiye VI. Tarla Bitkileri Kongresi. 5-9 Eylül Antalya.

[5] Sohrabı, Y., Heidari, G., Esmallpoor, B., 2007. Influence of Harvesting Time on Yield and Yield Components of Sugar Beet. Friends Science Publishers. 2. 69-73.

[6] Refay, Y.A., 2010. Root Yield and Quality Traits of Three Suga Beet (Beta vulgaris L.) Varieties in Relation to Sowing Date and Stand Densities .World Journal of Agricultural Sciences 6 (5) 589-594.

[7] Ahmad, S., Zubair, M., Iqbal, N., Cheema, M.N., Mahmood, K., 2012. Evaluation of Sugar Beet Hybrid Varieties under Thal-Kumbi Soil Series of Pakistan. International Journal of Agriculture and Biology. 14. 4. 605-608.

[8] Minx, L., Rikanov, J., 1987. Yeild Depression of Sugar Beet Caused by Gaps in Stands Sown on Different Dates. Rostlinna Vyroba. 33(9). 959964.

[9] Akçin, A., Mülayim, A., Yıldırım, B., Sade, B., Tamkoç, A., Önder, M., 1992. Şeker Pancarında (Beta vulgaris var saccharifera L.) Çeşit ve Ekim Zamanının Verim. Verim Unsurları ve Kalite Üzerine Etkileri. Doğa Türk Tarım ve Ormancılık Dergisi. 16. 4. 731-743.

[10] Durrant, M.J., Mash, S.J., Jaggard, K.W., 1993. Effects of Seed Advancement and Sowing Date on Establishment Bolting and Yield of Sugar Beet. Journal of Agricultural Science. 121. 3. 333-341.

[11] Kerr, S., Leaman, M., 1997. To water or not. British Sugar Beet Review, 65,11-3

[12] Glauert, W., 1983. Carbon Exchange of a Sugar Beet Crop Through a Season. University of Nottingham, Department of Crop Science, PhD Thesis, 120s.

[13] Hull, R., H., Webb, D., J., 1970. The Effect of Sowing Date and Harvesting Date on the Yield of Sugar Beet. Journal of Agricultural Science, Cambridge, 75, 223-229.

[14] Scott, R.K., English, S.D., Wood, D., W., Unsworth, M. H., 1973. The Yield of Sugar Beet in Relation to Weatherand Length of Growing Season. Journal of Agricultural Science, Cambridge, 81, 339-347.

[15] O' Connor, L.J., 1981. Factors Affecting Yield and Quality of Sugar Beet in Ireland. National University of Ireland, Department of Crop Science, Phd Thesis, 200p, Dublin.

[16] O' Donovan, T.M., 2002.The Effects of Seed Treatment, Sowing Date Cultivar and Harvest Date on theYield and Quality of Sugar Beet. National University of Ireland, M. Sc. Thesis,140p. Dublin.

[17] Harvey, C.W. and J.V. Dutton, 1993. Root quality and processing. The Sugar Beet Crop. Chapman and Hall, 675 p. London.

[18] Pocock, T., Milford, G.F.J., Armstrong. M., 1988. Progress in Research Toward Site Specific Fertiliser Requirements. Britisth Sugar Beet Review, 56,41-44.

[19] Kováč, K., 1998, The Effect of Different Soil Cultivation and Fertilization on Yield, Quality and Uptake of Nutrients in Sugar Beet Rostlinna Vyroba, 44, 59-64.

[20] Jozefyova, L., Pulkrabek, J., Urban, J., 2003. The Influence of Harvest Date and Crop Treatment on The Production of Two Different Sugar Beet 
Variety Types, Plant, Soil and Environment, 49(11), 495-498.

[21] Hozayn, M., Abd El-Monem A.A., Bakery A.A., 2013. Screening of Some Exotic Sugar Beet Cultivars Grown under Newlyre Claimed Sandy Soil for Yield and Sugar Quality Traits. Journal of Applied Sciences Research, 9(3), 2213-2222.

[22] Jozefyova, L.,Pulkrabek, J., Urbam, J., 2004. Effect of Harvest Time on Sugar Beet Fertilised with ;Increased Nitrogen. Science and Technology, 2, 232-237.

[23] Jama, M., Bahadar, K., 1988. Varietal Performance of Sugar Beet in Bannu Area of NWFP J. Pure Applied Science, 7: 7-8.

[24] Oad, F.C., Hameed, A., Ansari, B.K., Solangi, M.U., Khail, G.N., Oad, N.L., 2001. Performance Evaluation of Exotic Sugar Beet under Selected Agro-Climatic Conditions of Sindh Province. Internal Journal Agriculture Biology, 4, 472474.

[25] Khan, D., Khan, I., Khan,P., Rehman, G.,2004. Sugar Beet Cultivation in The Southern Parts of NWFP. Pakistan Sugar Journal, 19, 19-24.

[26] Ebrahimian, H.R.,Sadegheian, S.Y., Jahadakbar, M.R., Abbasi, Z., 2009. Study of Daptabilityand Stability of Sugar Beet Monogerm Cultivars in Different Locations of Iran. Journal Sugar Beet, $24,1-13$

[27] Johnson, R., T., Alexander, J., T., Rush, G., E., Hawkes, G., R., 1971. Advances in Sugar Beet Production Principlesand Practices (23-53).Çev. Bilgin, T., Erel, K., Onat, G. Türkiye Şeker Fabrikaları Yayınları, 479s, Ankara.
[28] Akınerdem, F., Sade, B., Acar, R., Soylu, S., 1996. Konya Şartlarında Şeker Pancarının (Beta vulgaris L.) Hasat Zamanının Belirlenmesi. Tübitak-Doğa Dergisi, 20, 139-143.

[29] Çakmakcl, R., Tingır, N., 2001. Vejetasyon Periyodunun Uzunluğunun Şeker Pancarının Gelișim Verim ve Kalite Üzerine Etkisi. Atatürk Üniversitesi Ziraat Fakültesi Dergisi, 32(1), 4149.

[30] Heidari, G., Sohrabi, Y., 2008. Influence of Withholding Irrigation and Harvest Times on Yield and Quality of Sugar Beet (Beta vulgaris L.). International Journal of Agriculture and Biology, 10(4), 427-431.

[31] Ada, R., 2010. Farklı Zamanlarda ve Tekniklerde Hasat Edilen Şeker Pancarında (Beta vulgaris saccharifera L.) Silolama Süresinin Verim ve Kalite Üzerine Etkisi. Selçuk Üniversitesi, Fen Bilimleri Enstitüsü, Doktora Tezi, 108s, Konya.

[32] Smit, A.L., 1993. The İnfluence of Sowing Date and Plant Density on The Decision to Resow Sugar Beet. Field Crops Research, 34, 159-173.

[33] Wärländer, B., 1992. Hoher Ertrag und hohe Qualität-ein Widerspruch beim Anbau von Zuckerrüben?. Zuckerindustrie, 117(11), pp.908-912.

[34] Lauer, J.G., 1997. Sugar beet performance and interactions with planting date, genotype, and harvest date. Agronomy journal, 89(3), pp.469475.

[35] Sögüt, T. and Aroglu, H., 2004. Plant density and sowing date effects on sugar beet yield and quality. Journal of Agron, 3(3), pp.215-218.

[36] Brown, S., 1997. Quality Harvesting Program. British Sugar Beet Review, 65, 12-3. 